\title{
An edge-cloud collaborative computing platform for building AloT applications efficiently
}

\section{Guoping Rong}

Nanjing University

Yangchen Xu ( $\nabla$ xuyangchen1997@foxmail.com )

Nanjing University https://orcid.org/0000-0002-6881-1809

Xinxin Tong

Transwarp Inc.

Haojun Fan

Transwarp Inc.

\section{Research Article}

Keywords: AloT application, edge-cloud collaborative computing, effciency

Posted Date: February 11th, 2021

DOl: https://doi.org/10.21203/rs.3.rs-218949/v1

License: (c) (1) This work is licensed under a Creative Commons Attribution 4.0 International License. Read Full License 


\section{Abstract}

The convergence of the Artificial Intelligence (Al) and the Internet of Things (IoT), i.e. the Artificial Intelligence of Things (AloT), is a very promising technology that redefines the way people interact with the surrounding devices. Practical AloT applications not only have high demands on computing and storage resources, but also desire for high responsiveness. Traditional cloud-based computing paradigm faces the great pressure on the network bandwidth and communication latency, hence the newly emerged edge computing paradigm gets involved. Consequently, AloT applications can be implemented in an edge-cloud collaborative manner, where the model building and model inferencing are offloaded to the cloud and the edge, respectively. However, developers still face challenges building AloT applications in practice due to the inherent heterogeneity of the loT devices, the declining accuracy of once trained models, the security and privacy issues, etc. In this paper, we present the design of an industrial edgecloud collaborative computing platform that aims to facilitate building AloT applications in practice. Furthermore, a real-world use case is presented in this paper, which proved the efficiency of building an AloT application on the platform.

\section{Full Text}

Due to technical limitations, full-text HTML conversion of this manuscript could not be completed. However, the manuscript can be downloaded and accessed as a PDF.

\section{Figures}


Training data

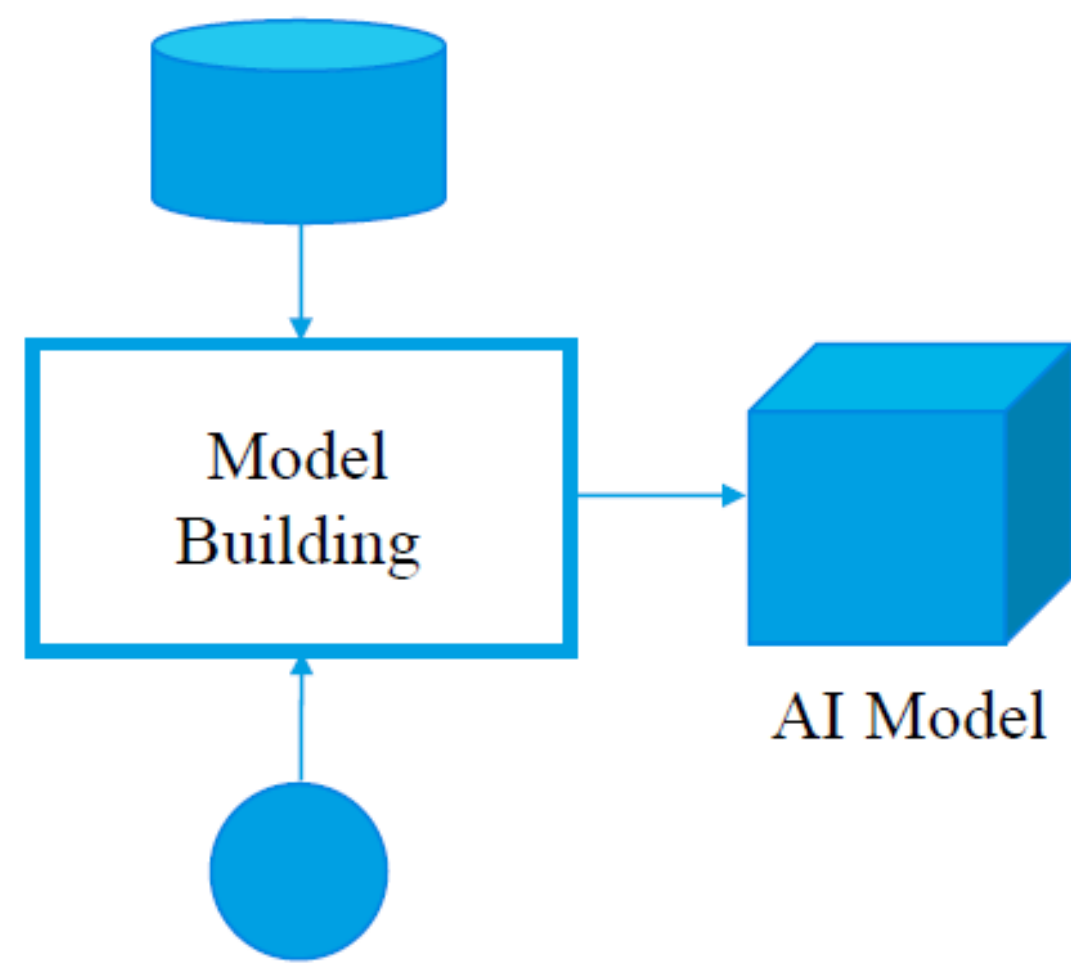

Algorithm
Input

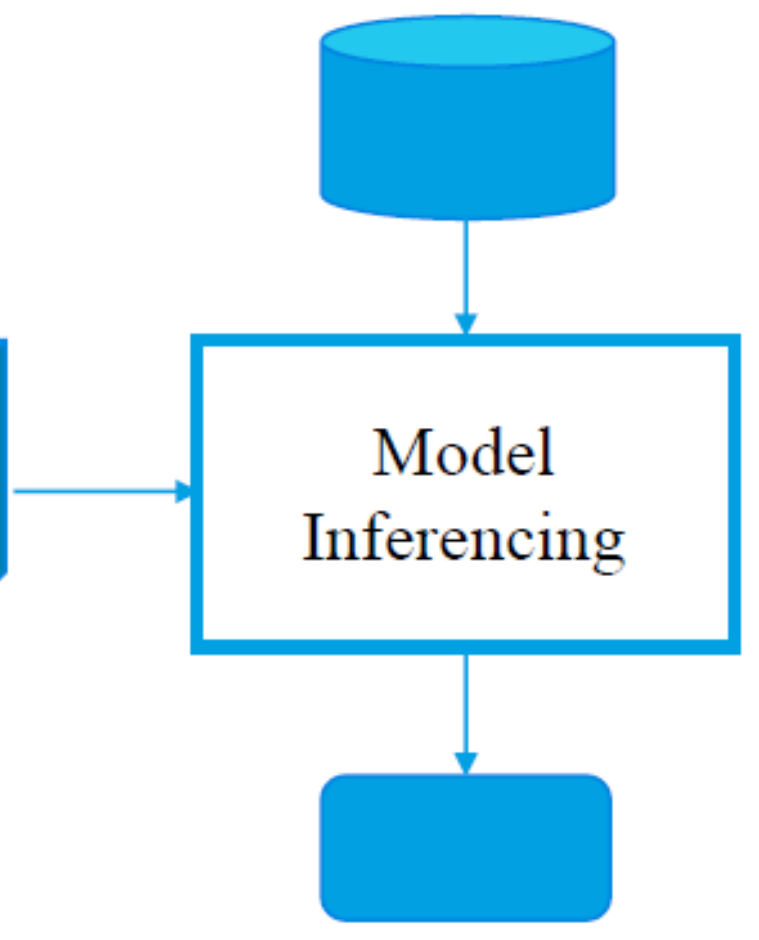

Result

Figure 1

Two-stage process of an Al approach based on [6] 


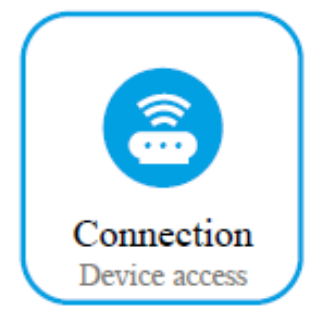

Device
Send

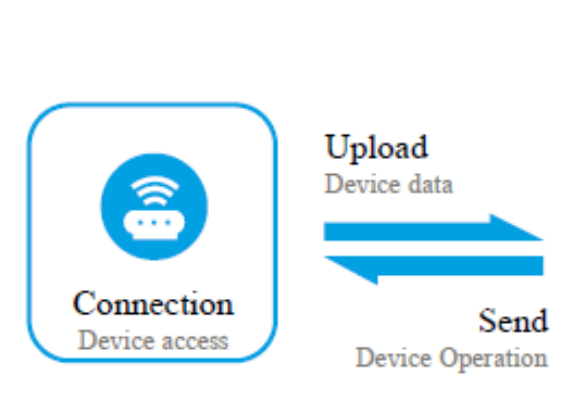

Device

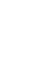

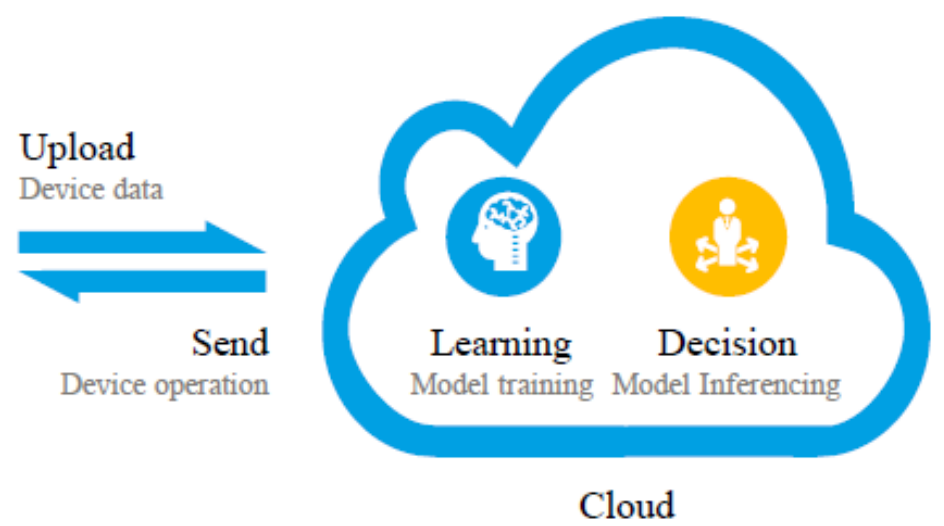

(a) Cloud-based AIoT

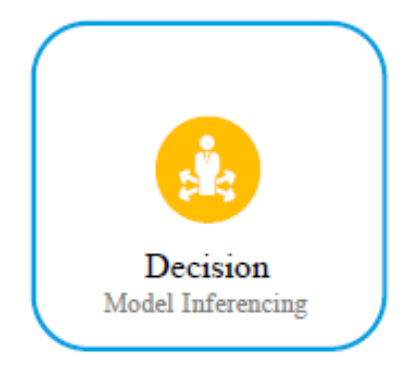

Edge
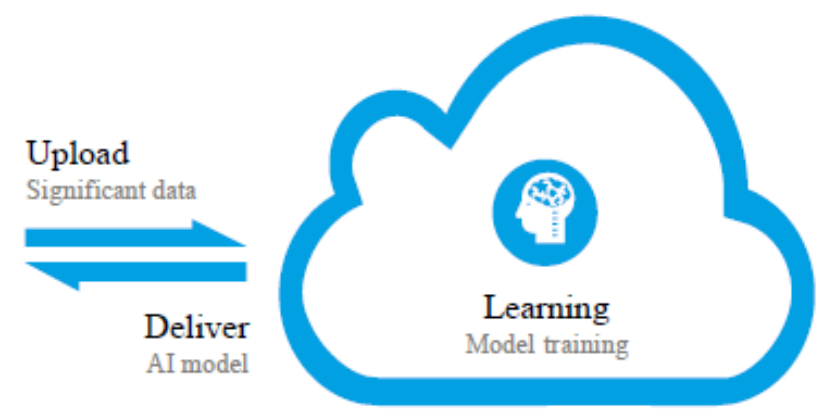

Cloud

(b) Edge-cloud collaborative AIoT

\section{Figure 2}

Two different paradigms of AloT

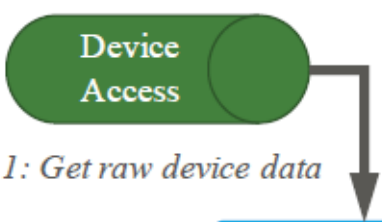

\section{Processing}

Stage 2: Process raw data into model input

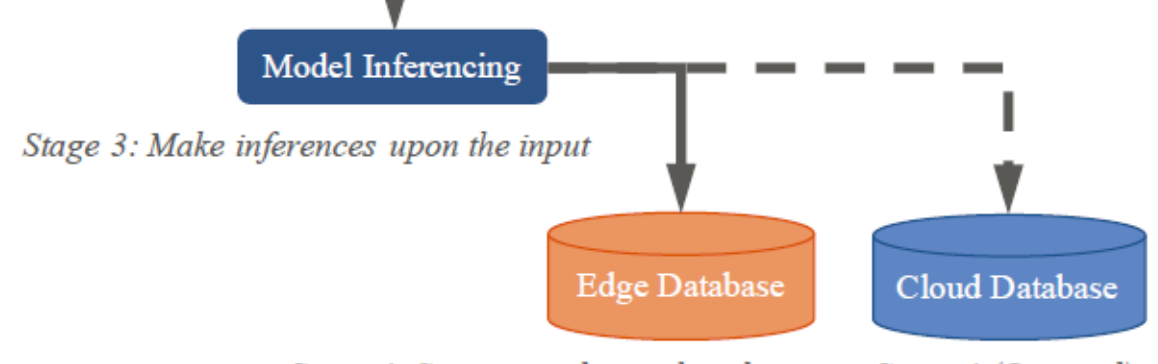

Stage 4: Saving results on the edge

Stage 4 (Optional): Sending results to the cloud

Figure 3 
A typical AloT pipeline

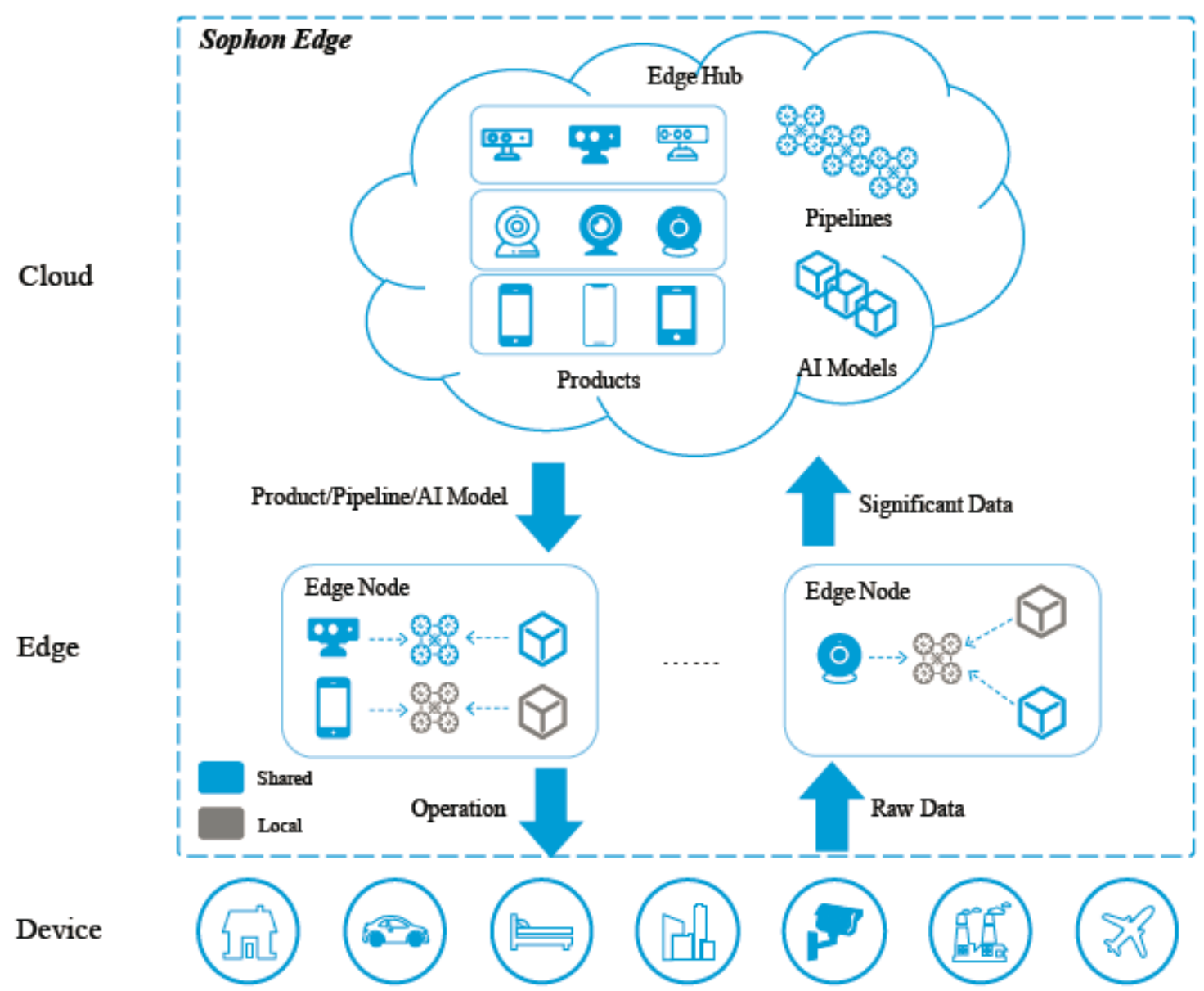

(a) High level overview

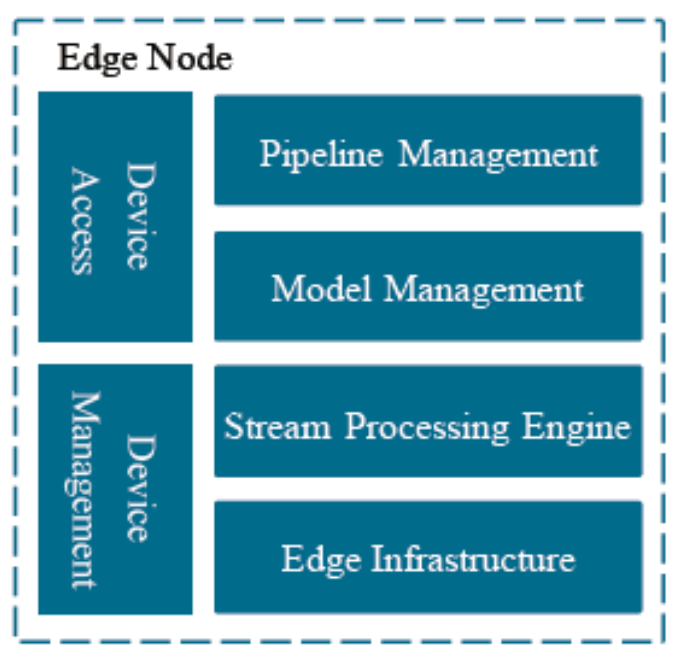

(b) Edge Node

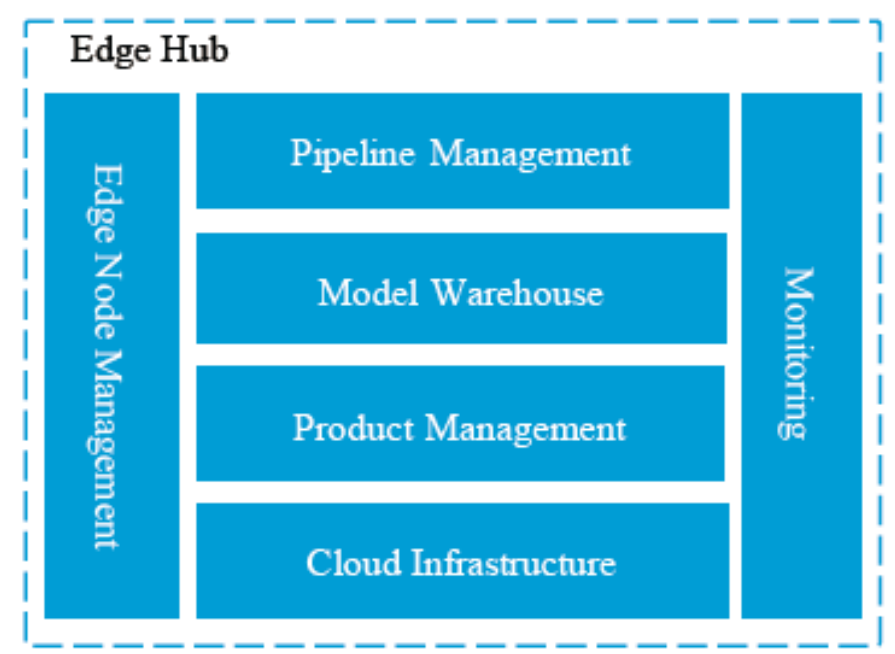

(c) Edge Hub

Figure 4

Platform architecture 


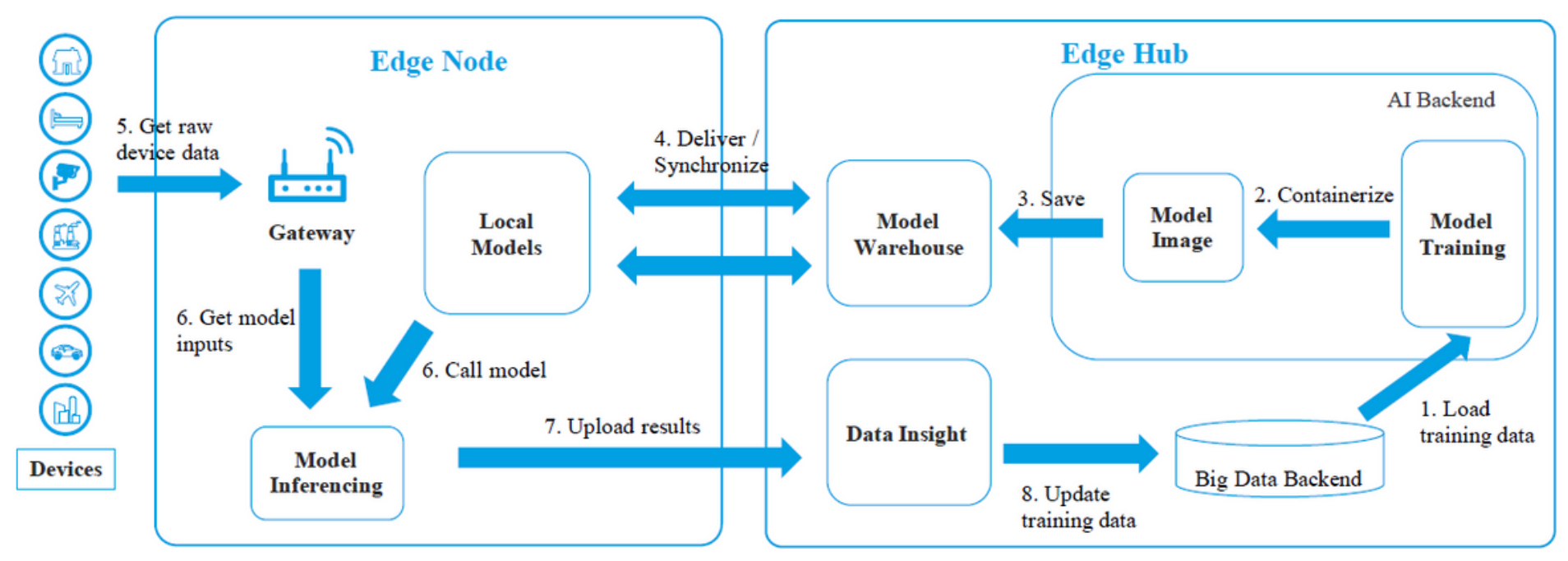

Figure 5

The process of model iteration 

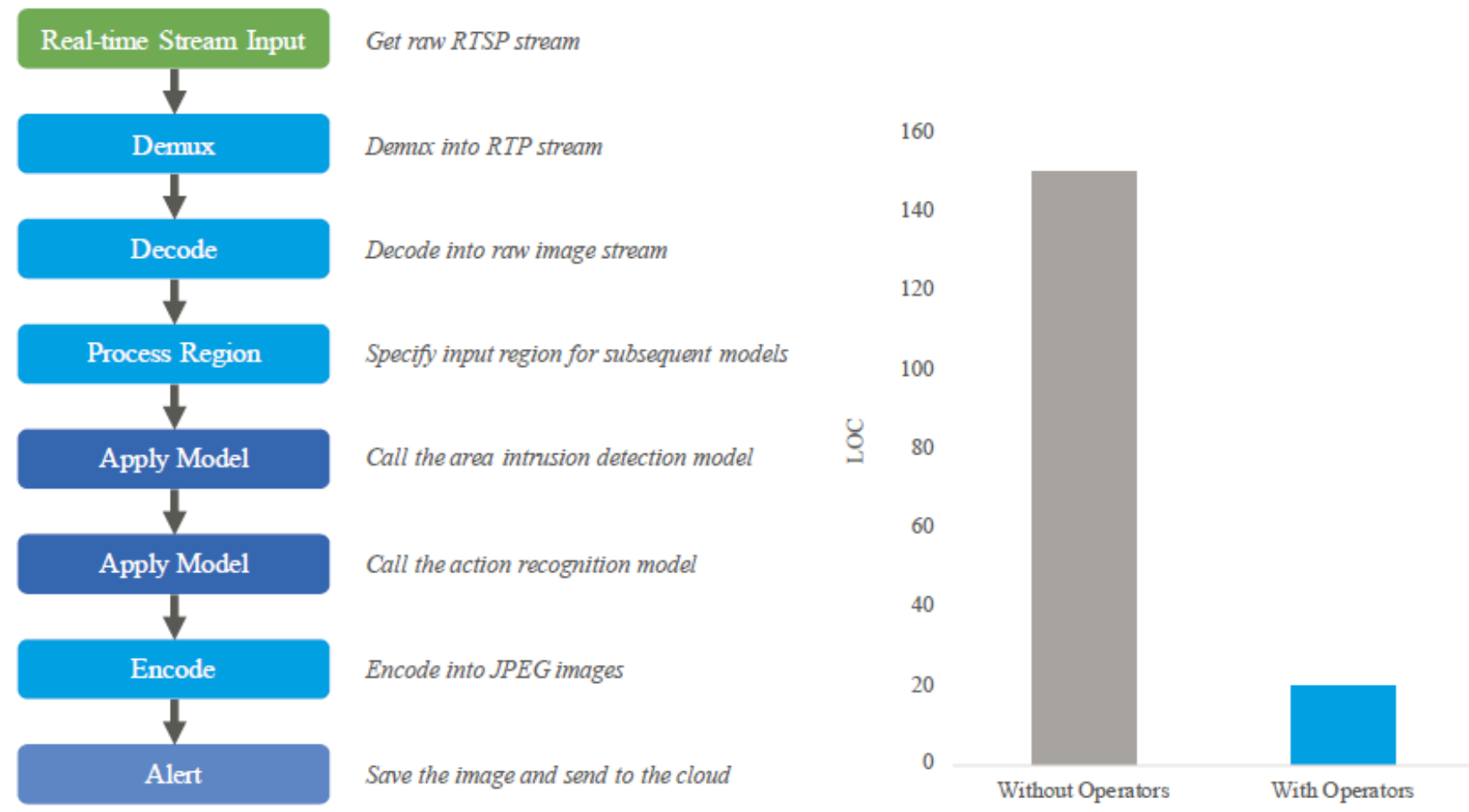

(a) The pipeline for sewage dumping behavior detection

(b) Lines of Code (LOC) required to build the pipeline

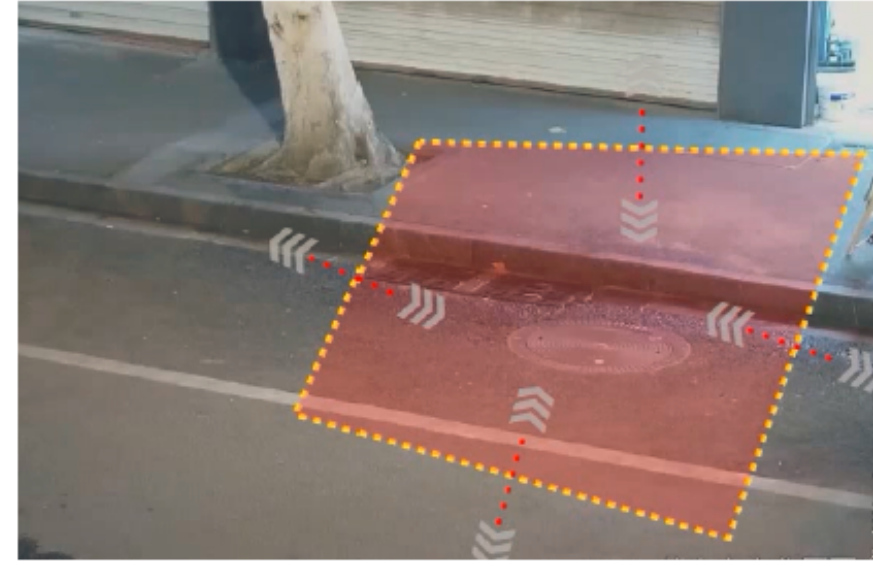

(c) Illustration of the "Process Region" operator

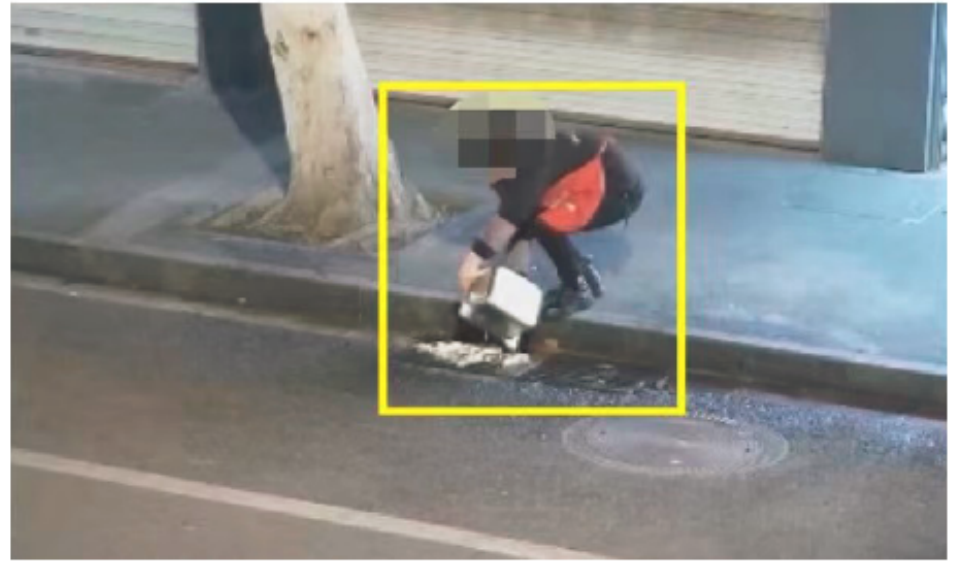

(d) A detected sewage dumping behavior

\section{Figure 6}

A use case of AloT in Smart City 